\title{
Audaciously under the Dome: Behavior Science in Systems and Society
}

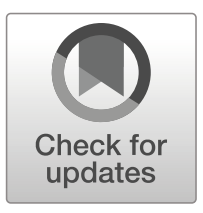

\author{
Donald A. Hantula ${ }^{1}$ \\ Published online: 26 November 2019 \\ (C) Association for Behavior Analysis International 2019
}

Operant research was never about counting key pecks, lever presses, switch closures, or keyboard taps. These easily indexed, convenient, sometimes arbitrary responses were adopted as a means to yield data that could tell us something about matters that were more grand and important than a relay pulse. The title of Skinner's (1938) seminal The Behavior of Organisms was criticized by contemporaries as an immodest overreach (Finan 1940; Hilgard 1939), but a more unassuming title such as "The Lever Pressing of the Rat" might quickly have relegated the book to dusty university library stacks and antiquarian bookstores. Instead, the book remains in print to this day ${ }^{1}$ because it was big, bold, and brash, and set the occasion for a science that could and would handle anything the world might throw at it, taking us from rats to human behavior (Skinner 1953) and from lever presses to language or in Skinner's (1957) terms, verbal behavior.

Other audacious extrapolations inspired by this work followed. A five-page paper describing the behavior of three pigeons (Herrnstein 1961) led to the matching law (Herrnstein 1970); a six-page report of choices by six pigeons (Ainslie and Herrnstein 1981) gave us the hyperbolic discount function. Both the matching law and hyperbolic discount function now challenge rational choice theory and the foundation of neoclassical economics (Herrnstein 1990) and helped usher in behavioral economics (Furrebøe and Sandaker 2017). The hyperbolic discount function spawned research in a wide range of topics from quotidian behaviors such as choices for consumer items (Fagerstrøm and Hantula 2013; Oliveira-Castro and Marques 2017) or employment (Schoenfelder and Hantula 2003) to serious social problems such as substance abuse (Green and Myerson 2019; Mitchell 2019). Indeed, work on discounting has become so sophisticated that discount functions can predict treatment

\footnotetext{
${ }^{1}$ Traditional paper copies or e-book copies of The Behavior of Organism may be purchased from the B. F. Skinner Foundation (https://www.bfskinner.org/bookstore-2/).
}

Donald A. Hantula

hantula@temple.edu 
outcomes (Stanger et al. 2012), relapse (Yoon et al. 2007), and may well be an index of a transdisease process that contributes to many disorders (Bickel et al. 2012; Bickel et al. 2015; Koffarnus et al. 2013).

The matching law and delay discounting are but two examples of the intellectual progress and social contributions that can be made by behavior scientists who retain rigor in research while looking to larger issues. Perhaps the catchphrase here should be "Study small, think big," or in keeping with the zeitgeist "small data, big ideas"2 This is not to encourage "Science and Human Behavior Lite" flights of fancy offering a speculative qualitative "analysis" of some "behavioral" issue, but rather to remind us that there is a bigger, more important picture looming above us as we carefully count responses.

Unfortunately, the decades since Skinner's first book have tended to grind away at its audacious agenda. Basic research seemed to slip into the sins of scholasticism, to the point of being labeled the "esoteric analysis of behavior" (Poling 2010, p. 8). Applied behavior analysis, which was supposed to provide the social justification for basic behavioral research, can seem so constricted in its methodological practices as to exclude problems of great social significance from its oeuvre (Cataldo 2017; Critchfield and Reed 2017; Friman 2017; Hyten 2017), focusing more and more on smaller and smaller segments of the population (Axelrod et al. 2012; Federov in press). According to Applied Behavior Analysis' (ABA) founding article (Baer et al. 1968) the term "applied" refers not to any particular procedure but the degree to which the behavior in question is "socially important." However, the "social importance" construct is rarely interrogated. Instead, it appears to be taken as self-evident that any behavior exhibited by an individual with a disability is "socially important." Without careful consideration of how "social importance" is determined and defined, by whom, and under what circumstances, the supposed societal value of applied behavior analysis may be called into question. In a strange twist of fate, an applied movement that was supposed to be beneficial to the experimental side of the field could ultimately prove to be detrimental. With its limited methodology, constrained populations, and debatable social relevance, it may be fair to now refer to ABA as "attenuated behavior analysis."

\section{In This Issue: From the Tails to the Top}

The narrow niches that both the experimental analysis of behavior and applied behavior analysis devolved into and now occupy might be comfortable, but ultimately they are self-defeating. Certainly there is much to be said for careful systematic science and also for the applications of behavior science that have helped the most vulnerable of our fellow humans. However, there is more to be said for tackling the challenges, issues, and problems that vex the larger population. This editorial's title is a tip of the keyboard to Pat Friman's (2006) excellent article exhorting ABAI members to turn their attention to the $68 \%$ of the population that may be found within \pm 1 standard deviation of the mean. In Friman's terms, we should look "under the dome" of the normal distribution:

\footnotetext{
${ }^{2}$ For those drowning in the "big data is the future" wave here is a lifeline. Among the data science cognoscenti, "small data" is the next big thing (Fahey 2019; Faraway and Augustin 2018; Idrus 2019; Lundquist 2013; Michel 2018; Show me the data 2019).
} 
instead of focusing on the small slice of the population that comprises the distribution's tails, we should spotlight its center of the distribution.

In short, we must emerge from the tails to engage with the larger world, and an increasing number of scholars are doing so. Some have advanced suggestions for other fields and issues that could benefit from a behavioral approach (Friman 2010; Normand and Kohn 2013). Others, such as those who work in Organizational behavior management (OBM) have been "under the dome" from the beginning (Hyten 2017). The recent pages of $P o B S$ are filled with articles taking on topics under the dome such as incarceration (Apel and Diller 2017), consumer behavior (Foxall 2017), higher education (Brodsky and Fienup 2018), progressive political movements (Mattaini and Aspholm 2016), narrative (Hineline 2018), leadership (Houmanfar and Mattaini 2016), the "replication crisis" (Laraway et al. 2019), connectionist models of human and computer learning (Ninness et al. 2018), healthy eating (Rafacz 2019; Sigurdsson et al. 2017), poverty (Silverman et al. 2019), conditioning plants (Adelman 2018), understanding concepts (Layng 2019), flirtation (Wade 2018), and maternal health (Washio and Humphreys 2018).

Friman (2006) advocated expanding our populations of interest. This issue's articles take the idea a step further, with two special sections showing how we can expand our units of analysis to expand both our populations of interest and our units of analysis. Traci Cihon and Mark Mattaini organized and edited a special section on cultural and behavioral systems science. This section is a fascinating collection of articles addressing such topics as cultural practices, corruption, aggression, metacontingencies, and selforganizing systems. Heather McGee and Manny Rodriguez assembled a special section, "Organizational Behavior Management in Health and Human Services," comprised of a selected group of papers from the ABAI preconference meeting of the same title. OBM applications in human services are well-researched (Gravina et al. 2018) and its expansion into health care looks promising (Kelley and Gravina 2018). In both special sections, we see how behavior science can be employed to understand topics that are clearly under the dome - culture, child attachment, prosocial behavior, service delivery, occupational safety. An important lesson to be learned from these two special sections is that if the world will not come to behavior science and behavior analysis, then behavior science and behavior analysis must go to the world. It is time that we lost our tails.

\section{Thanks and Recognition for a Job Well Done}

In what would be his final Thanksgiving proclamation (issued prior to his assassination), U.S. President Kennedy said in 1963, “As we express our gratitude, we must never forget that the highest appreciation is not to utter words but to live by them." PoBS editorial board members' exemplary efforts in scholarship and service provide us all with models to live by. Each editorial board member is an active and first-rate researcher who generously dedicated time to improve the journal and the field as a whole.

Editorial board members' work in loose collaboration with authors, so their contributions are largely unseen, yet no journal can prosper without them. PoBS editorial board members have been exemplary in providing timely, in-depth, and helpful reviews. Our editorial board members make good articles better and provide invaluable constructive feedback to authors of articles that we cannot accept. Through their efforts, 
PoBS now publishes many more articles than ever before, boasts a 44-day mean time to initial decision and an impact factor of 2.46. But beyond these contributions, the PoBS editorial board continues to be an excellent source of ideas, guidance, and counsel as we have made a transition into a wide-ranging quarterly journal of behavior science. I thank outgoing editorial board members John Borrero, José E. Burgos, Traci M. Cihon, Anthony DeFullio, Iser G. DeLeon, Ronnie Detrich, Wendy Donlin Washington, Claudia Drossel, Tim Hackenberg, Marta Hubner, Elizabeth Kyonka, Jack McDowell, Jonathon R. Miller, Suzanne H. Mitchell, Nancy A. Neef, Christopher Podlesnik, and Claire C. St. Peter for their hard work, expert reviews, and sage advice over the past 2 years. They have served the journal and our science with great distinction.

\section{The Last Waltz}

With this issue my term as editor-in-chief of $P o B S$ is completed. I am grateful for the support and encouragement offered over the last 3 years by the ABAI Publications Council, ABAI Executive Council, ABAI Executive Director Maria Malott, PoBS editorial board members, and authors of the articles we published (and of those articles we did not publish). I am especially grateful to associate editors Tom Critchfield, Erin Rasmussen, Dave Jarmolowicz, and Ingunn Sandaker. Their tireless work on behalf of PoBS, sage counsel, good humor, grace under deadline pressure, and tolerance of multiple late night emails made the journal into what it is today. When this first editorial team (Tom Critchfield and Erin Rasmussen) signed on in 2016 we set an audacious goal: that ABAI's flagship journal would be a top scholarly journal that reflects the full complement of topics that behavior science can address. We strategized and discussed and developed a plan to rebrand and redirect the journal to meet the challenges of research and scholarly publishing in the $21^{\text {st }}$ century. As submissions flourished we added Dave Jarmolowicz and Ingunn Sandaker to the editorial team. After 3 years, it looks like we made it. $P o B S$ grew into a quarterly journal that boasts hundreds of thousands of downloads from Springer's site alone, an enviable impact factor, and an expanded scope of articles, new online supplements (video, software, data), and a bright future. We leave PoBS in Chris Newland's capable hands and look forward to reading the groundbreaking articles that will appear with his careful guidance.

Acknowledgements I thank Tom Critchfield for his comments on this manuscript.

\section{References}

Adelman, B. E. (2018). On the conditioning of plants: A review of experimental evidence. Perspectives on Behavior Science, 41(2), 431-446. https://doi.org/10.1007/s40614-018-0173-6.

Ainslie, G., \& Herrnstein, R. J. (1981). Preference reversal and delayed reinforcement. Animal Learning \& Behavior, 9(4), 476-482. https://doi.org/10.3758/BF03209777.

Apel, A. B., \& Diller, J. W. (2017). Prison as punishment: A behavior-analytic evaluation of incarceration. The Behavior Analyst, 40(1), 243-256. https://doi.org/10.1007/s40614-016-0081-6. 
Axelrod, S., McElrath, K. K., \& Wine, B. (2012). Applied behavior analysis: Autism and beyond. Behavioral Interventions, 27(1), 1-15. https://doi.org/10.1002/bin.1335.

Baer, D. M., Wolf, M. M., \& Risley, T. R. (1968). Some current dimensions of applied behavior analysis. Journal of Applied Behavior Analysis, 1(1), 91-97. https://doi.org/10.1901/jaba.1968.1-91.

Bickel, W. K., Jarmolowicz, D. P., Mueller, E. T., Koffarnus, M. N., \& Gatchalian, K. M. (2012). Excessive discounting of delayed reinforcers as a trans-disease process contributing to addiction and other diseaserelated vulnerabilities: Emerging evidence. Pharmacology \& Therapeutics, 134, 287-297.

Bickel, W. K., Quisenberry, A. J., Moody, L., \& Wilson, A. G. (2015). Therapeutic opportunities for selfcontrol repair in addiction and related disorders: Change and the limits of change in trans-disease processes. Clinical Psychological Science, 3(1), 140-153. https://doi.org/10.1177/2167702614541260.

Brodsky, J., \& Fienup, D. M. (2018). Sidman goes to college: A meta-analysis of equivalence-based instruction in higher education. Perspectives on Behavior Science, 41(1), 95-119. https://doi. org/10.1007/s40614-018-0150-0.

Cataldo, M. F. (2017). Driving with the rear view mirror. The Behavior Analyst, 40(1), 161-165. https://doi. org/10.1007/s40614-017-0103-z.

Critchfield, T. S., \& Reed, D. D. (2017). The fuzzy concept of applied behavior analysis research. The Behavior Analyst, 40(1), 123-159. https://doi.org/10.1007/s40614-017-0093-x.

Fagerstrøm, A., \& Hantula, D. A. (2013). Buy it now and pay for it later: An experimental study of student credit card use. The Psychological Record, 63(2), 323-332. https://doi.org/10.11133/j.tpr.2013.63.2.007.

Fahey, L. (2019). Getting to insight: the value and use of small data. Strategy \& Leadership, 47(3), 27-33. https://doi.org/10.1108/SL-03-2019-0034.

Faraway, J. J., \& Augustin, N. H. (2018). When small data beats big data. Statistics \& Probability Letters, 136, 142-145. https://doi.org/10.1016/j.spl.2018.02.031.

Federov, A. (in press). Publishing about autism spectrum disorder in the Journal of Applied Behavior Analysis and the Journal of the Experimental Analysis of Behavior: Bibliometric analysis (1958-2017). Journal of Behaviorology.

Finan, J. (1940). Review of The behavior of organisms. Journal of General Psychology, 22, 441-447.

Foxall, G. R. (2017). Behavioral economics in consumer behavior analysis. The Behavior Analyst, 40, 309313.

Friman, P. C. (2006). The future of applied behavior analysis is under the dome. ABA Newsletter, 29, 4-7.

Friman, P. C. (2010). Come on in, the water is fine: Achieving mainstream relevance through integration with primary medical care. The Behavior Analyst, 33(1), 19-36. https://oi.org/10.1007/bf03392201.

Friman, P. C. (2017). You are in the way! Opening lines of transmission for Skinner's view of behavior. The Behavior Analyst, 40(1), 173-177.

Furrebøe, E. F., \& Sandaker, I. (2017). Contributions of behavior analysis to behavioral economics. The Behavior Analyst, 40(2), 315-327. https://doi.org/10.1007/s40614-017-0110-0.

Gravina, N., Villacorta, J., Albert, K., Clark, R., Curry, S., \& Wilder, D. (2018). A literature review of organizational behavior management interventions in human service settings from 1990 to 2016. Journal of Organizational Behavior Management, 38(2-3), 191-224. https://doi.org/10.1080 /01608061.2018.1454872.

Green, L., \& Myerson, J. (2019). On the complexity of discounting, choice situations, and people. Perspectives on Behavior Science, 42(3), 433-443. https://doi.org/10.1007/s40614-019-00209-y.

Herrnstein, R. J. (1961). Relative and absolute strength of response as a function of frequency of reinforcement. Journal of the Experimental Analysis of Behavior, 4(3), 267-272. https://doi.org/10.1901 /jeab.1961.4-267.

Herrnstein, R. J. (1970). On the law of effect. Journal of Experimental Analysis of Behavior, 13, $243-266$. https://doi.org/10.1901/jeab.1970.13-243.

Herrnstein, R. J. (1990). Rational choice theory: Necessary but not sufficient. American Psychologist, 45(3), 356-367. https://doi.org/10.1037/0003-066X.45.3.356.

Hilgard, E. R. (1939). Review of The behavior of organisms. Psychological Bulletin, 36(2), 121-125.

Hineline, P. N. (2018). Narrative: Why it's important, and how it works. Perspectives on Behavior Science, 41(2), 471-501. https://doi.org/10.1007/s40614-018-0137-x.

Houmanfar, R. A., \& Mattaini, M. A. (2016). Leadership and cultural change: Implications for behavior analysis. The Behavior Analyst, 39(1), 41-46. https://doi.org/10.1007/s40614-016-0064-7.

Hyten, C. (2017). OBM is already using the "fuzzy concept" criteria for applied behavioral research: Commentary on Critchfield and Reed. The Behavior Analyst, 40(1), 179-182. https://doi.org/10.1007 /s40614-017-0096-7.

Idrus, A. A. (2019). Unlocking small data, the "next frontier" in drug discovery. FierceBiotech, https://www. fiercebiotech.com/biotech/unlocking-small-data-next-frontier-drug-discovery 
Kelley, D. P., \& Gravina, N. (2018). A paradigm shift in healthcare: An open door for organizational behavior management. Journal of Organizational Behavior Management, 38(1), 73-89. https://doi.org/10.1080 /01608061.2017.1325824.

Kennedy, J. F. (1963). Proclamation 3560-Thanksgiving Day, 1963. The American Presidency Project, https://www.presidency.ucsb.edu/node/236639

Koffarnus, M. N., Jarmolowicz, D. P., Mueller, E. T., \& Bickel, W. K. (2013). Changing delay discounting in the light of the competing neurobehavioral decision systems theory: A review. Journal of the Experimental Analysis of Behavior, 99(1), 32-57. https://doi.org/10.1002/jeab.2.

Laraway, S., Snycerski, S., Pradhan, S., \& Huitema, B. E. (2019). An overview of scientific reproducibility: Consideration of relevant issues for behavior science/analysis. Perspectives on Behavior Science, 42(1), 33-57. https://doi.org/10.1007/s40614-019-00193-3.

Layng, T. V. J. (2019). Tutorial: Understanding concepts: Implications for behavior analysts and educators. Perspectives on Behavior Science, 42(2), 345-363.

Lundquist, E. (2013). "Small data" analysis the next big thing, advocates assert. eWeek, 11, 11.

Mattaini, M. A., \& Aspholm, R. (2016). Contributions of behavioral systems science to leadership for a new progressive movement. The Behavior Analyst, 39(1), 109-121. https://doi.org/10.1007/s40614-015-0043-4.

Michel, N. (2018). Big data is great, but don't overlook the power of small data. Promotional Marketing, 1, 1.

Mitchell, S. H. (2019). Linking delay discounting and substance use disorders: Genotypes and phenotypes. Perspectives on Behavior Science. https://doi.org/10.1007/s40614-019-00218-x.

Ninness, C., Ninness, S. K., Rumph, M., \& Lawson, D. (2018). The emergence of stimulus relations: Human and computer learning. Perspectives on Behavior Science, 41(1), 121-154.

Normand, M. P., \& Kohn, C. S. (2013). Don't wag the dog: Extending the reach of applied behavior analysis. The Behavior Analyst, 36(1), 109-122. https://doi.org/10.1007/BF03392294.

Oliveira-Castro, J. M., \& Marques, R. S. (2017). Temporal discounting and marketing variables: Effects of product prices and brand informational reinforcement. The Behavior Analyst, 40(2), 475-492. https://doi. org/10.1007/s40614-017-0109-6.

Poling, A. (2010). Looking to the future: Will behavior analysis survive and prosper? The Behavior Analyst, 33(1), 7-17. https://doi.org/10.1007/BF03392200.

Rafacz, S. D. (2019). Healthy eating: Approaching the selection, preparation, and consumption of healthy food as choice behavior. Perspectives on Behavior Science, 42(3), 647-674. https://doi.org/10.1007/s40614018-00190-y.

Schoenfelder, T. E., \& Hantula, D. A. (2003). A job with a future? Delay discounting, magnitude effects, and domain independence of utility for career decisions. Journal of Vocational Behavior, 62(1), 43-55. https://doi.org/10.1016/S0001-8791(02)00032-5.

Show me the data. (2019). How understanding small data can help give organizational foresight. Strategic Direction, 35(9), 11-12.

Sigurdsson, V., Menon, V. R. G., \& Fagerstrøm, A. (2017). Online healthy food experiments: Capturing complexity by using choice-based conjoint analysis. The Behavior Analyst, 40, 373-391.

Silverman, K., Holtyn, A. F., \& Toegel, F. (2019). The utility of operant conditioning to address poverty and drug addiction. Perspectives on Behavior Science, 42(3), 525-546. https://doi.org/10.1007/s40614-019$00203-4$

Skinner, B. F. (1938). The behavior of organisms: An experimental analysis. Oxford: Appleton-Century.

Skinner, B. F. (1953). Science and human behavior. Oxford: Macmillan

Skinner, B. F. (1957). Verbal behavior. New York: Appleton-Century-Crofts.

Stanger, C., Ryan, S. R., Fu, H., Landes, R. D., Jones, B. A., Bickel, W. K., \& Budney, A. J. (2012). Delay discounting predicts adolescent substance abuse treatment outcome. Experimental \& Clinical Psychopharmacology, 20(3), 205-212. https://doi.org/10.1037/a0026543.

Wade, J. A. (2018). (I think) you are pretty: A behavior analytic conceptualization of flirtation. Perspectives on Behavior Science, 41(2), 615-636. https://doi.org/10.1007/s40614-018-0136-y.

Washio, Y., \& Humphreys, M. (2018). Maternal behavioral health: Fertile ground for behavior analysis. Perspectives on Behavior Science, 41(2), 637-652. https://doi.org/10.1007/s40614-018-0143-z.

Yoon, J. H., Higgins, S. T., Heil, S. H., Sugarbaker, R. J., Thomas, C. S., \& Badger, G. J. (2007). Delay discounting predicts postpartum relapse to cigarette smoking among pregnant women. Experimental \& Clinical Psychopharmacology, 15(2), 176-186. https://doi.org/10.1037/1064-1297.15.2.186.

Publisher's Note Springer Nature remains neutral with regard to jurisdictional claims in published maps and institutional affiliations. 